\title{
Unexpected Retroaldol-Aldol Reaction during $O$-Alkylation of Hydroxylated Vince Lactam Derivatives
}

\author{
Christoffer Bengtsson, Alexander Wetzel, Joakim Bergman and Jonas Brånalt* \\ Depratment of Medicinal Chemistry,CVMD iMed, AstraZeneca R\&D Mölndal SE-431 83, Sweden \\ jonas.branalt@astrazeneca.com
}

\section{Supporting information}

\section{Table of Contents}

${ }^{1} \mathrm{H}$-, and ${ }^{13} \mathrm{C}-\mathrm{NMR}$ spectra of new compounds..................S2-S24

NMR-study of the formation of enolate $12 \ldots \ldots \ldots \ldots \ldots \ldots . . . . . . .525-S 26$ 
${ }^{1} \mathrm{H}$ - and ${ }^{13} \mathrm{C}$-NMR of $\mathbf{2 a}$ in $\mathrm{CDCl}_{3}$
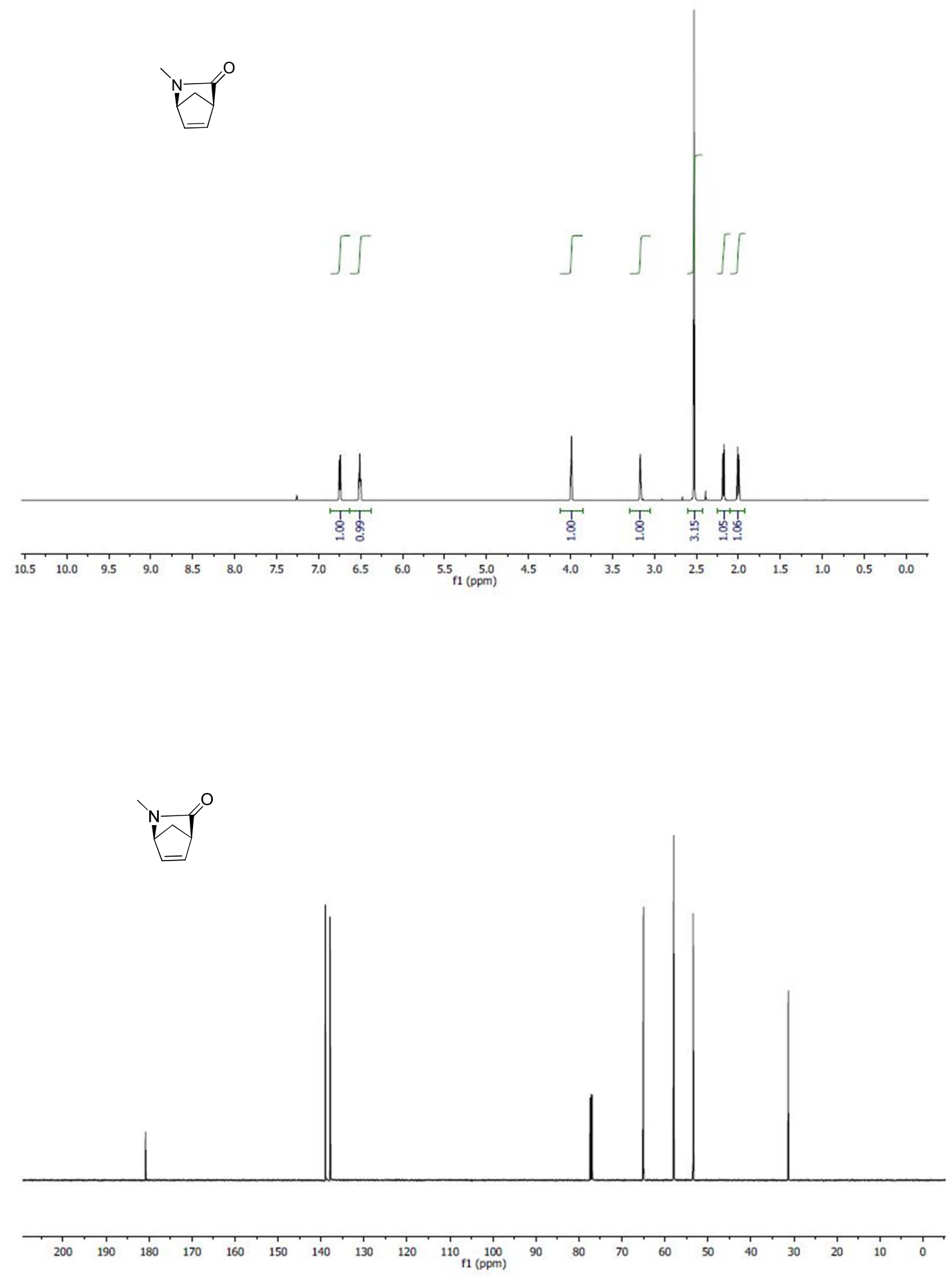
${ }^{1} \mathrm{H}$ - and ${ }^{13} \mathrm{C}-\mathrm{NMR}$ of compound $\mathbf{2 b}$ in $\mathrm{CDCl}_{3}$
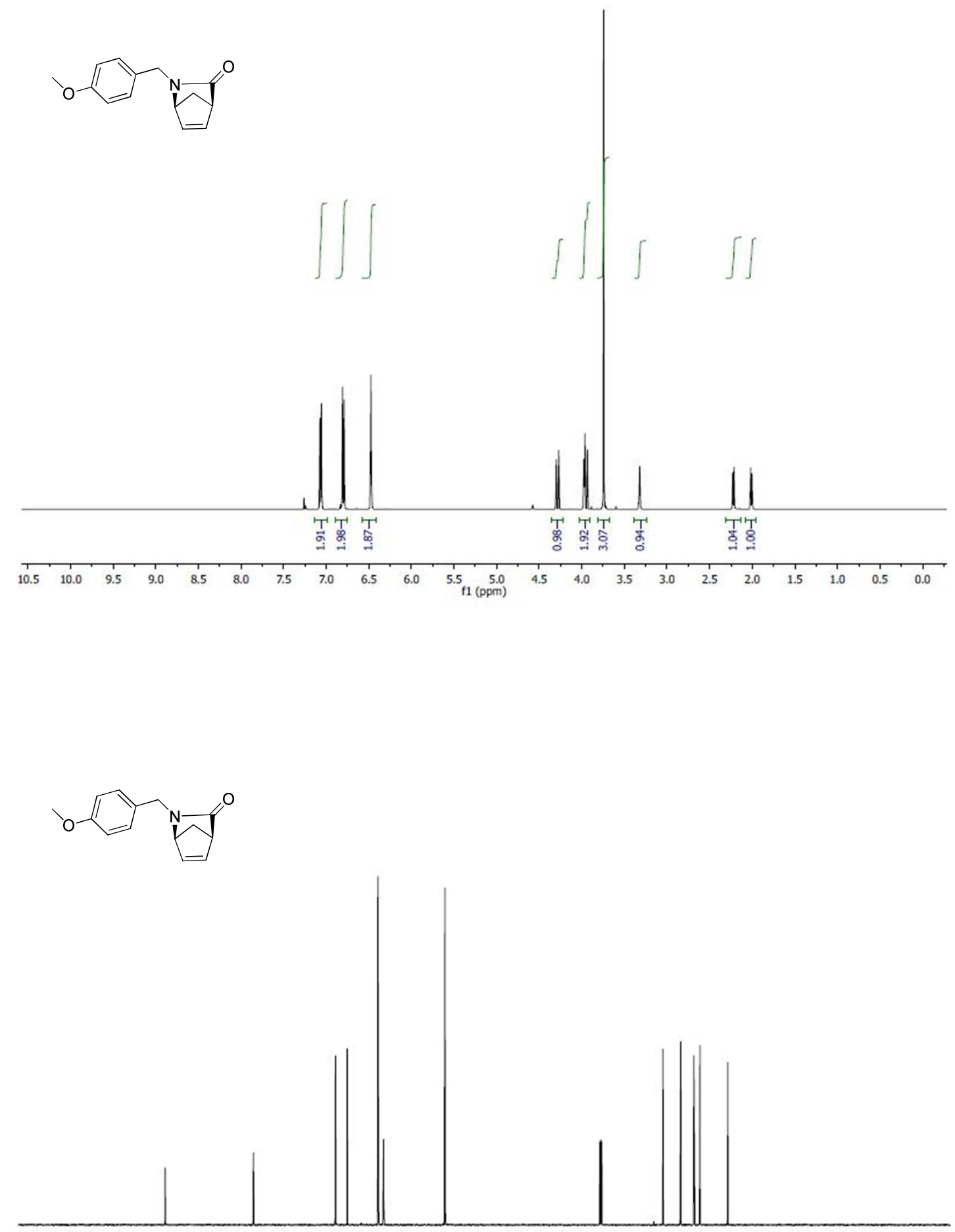

\begin{tabular}{lllllllllllllllllllllllllll}
\hline 210 & 200 & 190 & 180 & 170 & 160 & 150 & 140 & 130 & 120 & $\underset{f 1}{110} \underset{(\mathrm{ppm})}{100}$ & 90 & 80 & 70 & 60 & 50 & 40 & 30 & 20 & 10 & 0
\end{tabular} 
${ }^{1} \mathrm{H}$ - and ${ }^{13} \mathrm{C}-\mathrm{NMR}$ of compound $\mathbf{3 a}$ in $\mathrm{CDCl}_{3}$
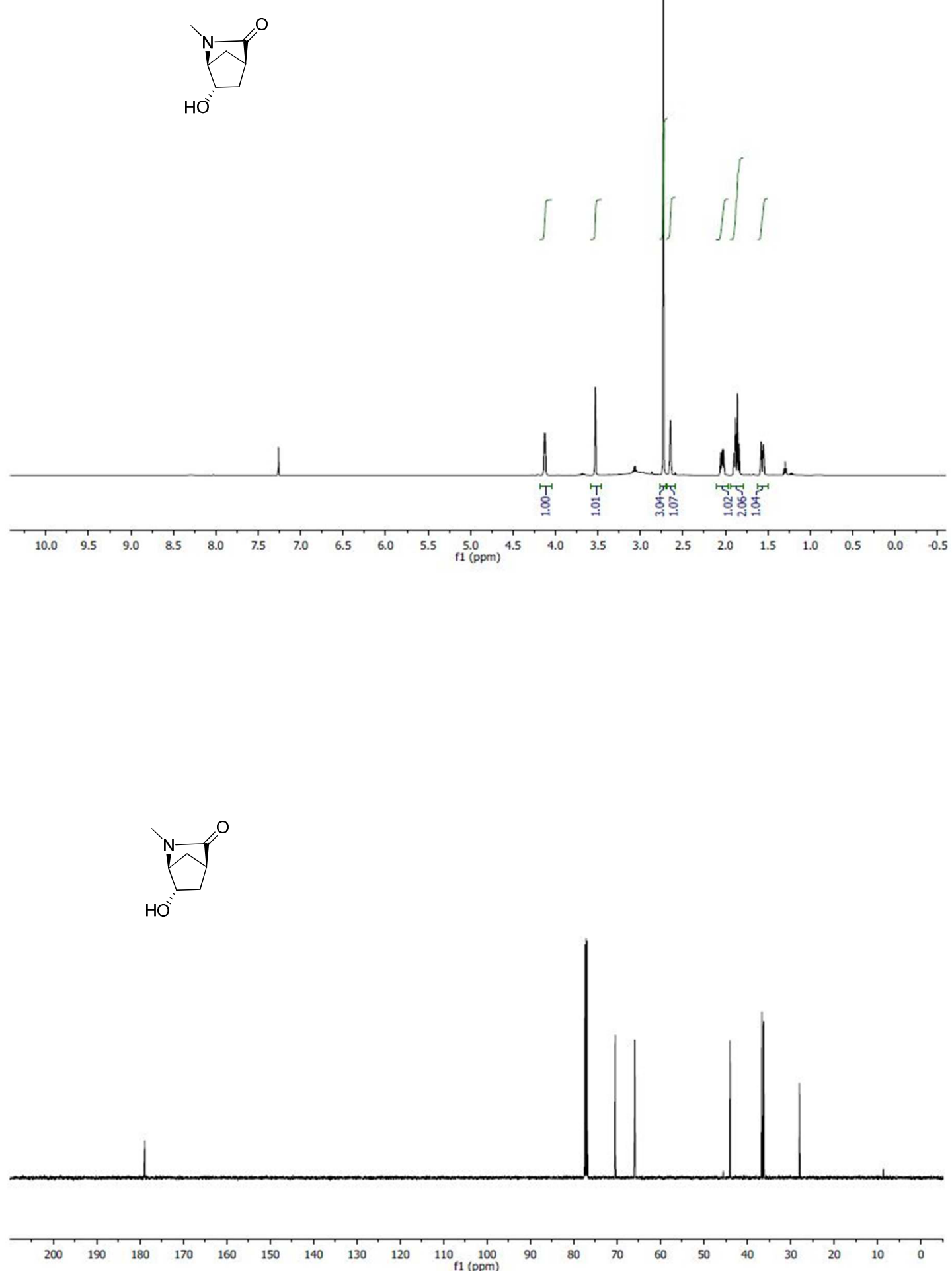
${ }^{1} \mathrm{H}$ - and ${ }^{13} \mathrm{C}-\mathrm{NMR}$ of compound $\mathbf{3 b}$ in $\mathrm{d}_{6}$-DMSO
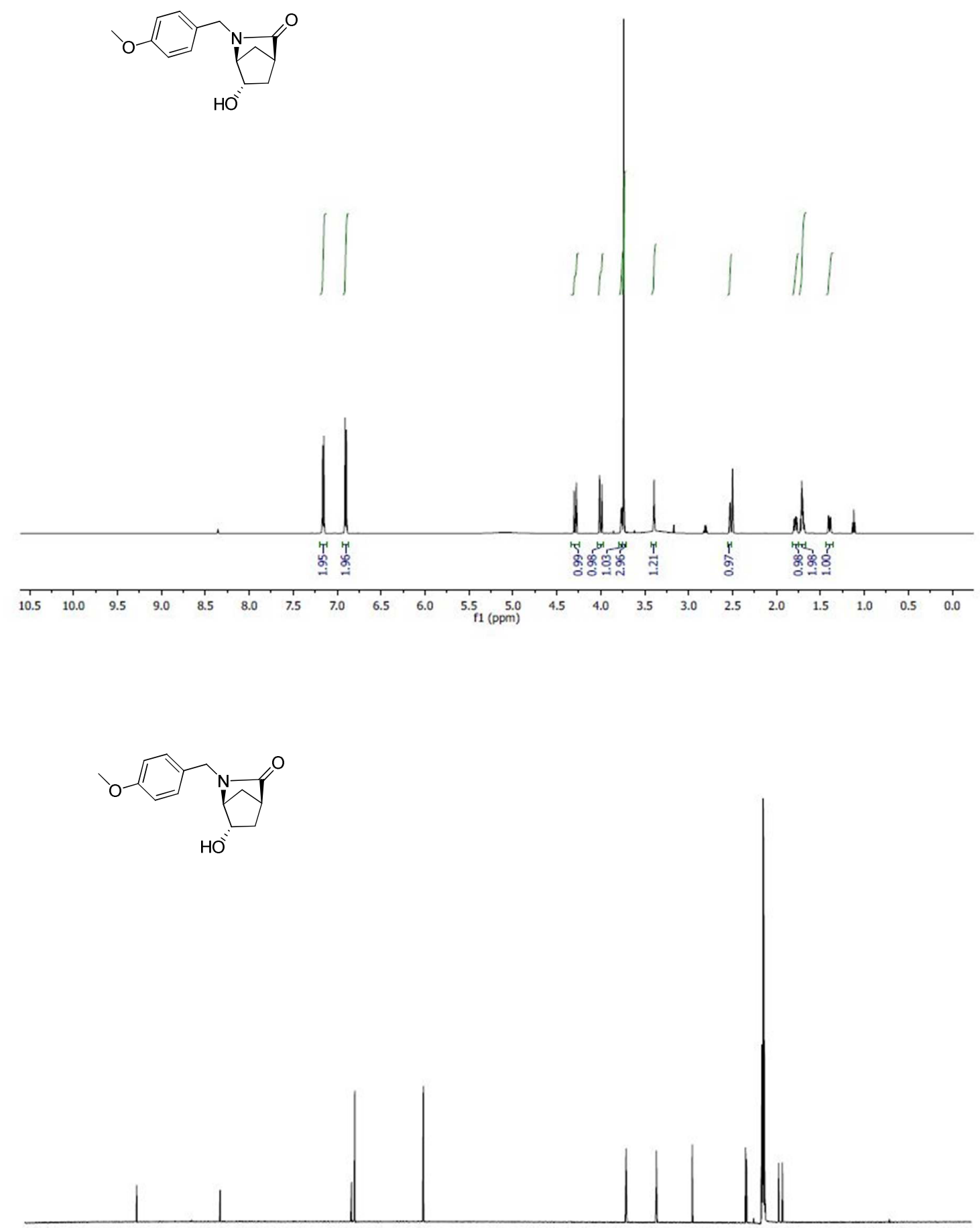

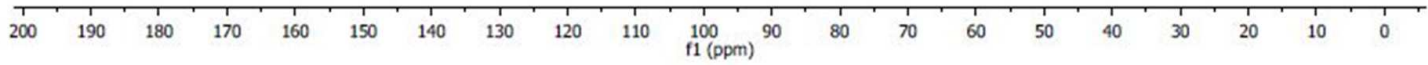


${ }^{1} \mathrm{H}$ - and ${ }^{13} \mathrm{C}-\mathrm{NMR}$ of compound $\mathbf{4 a}$ in $\mathrm{CDCl}_{3}$
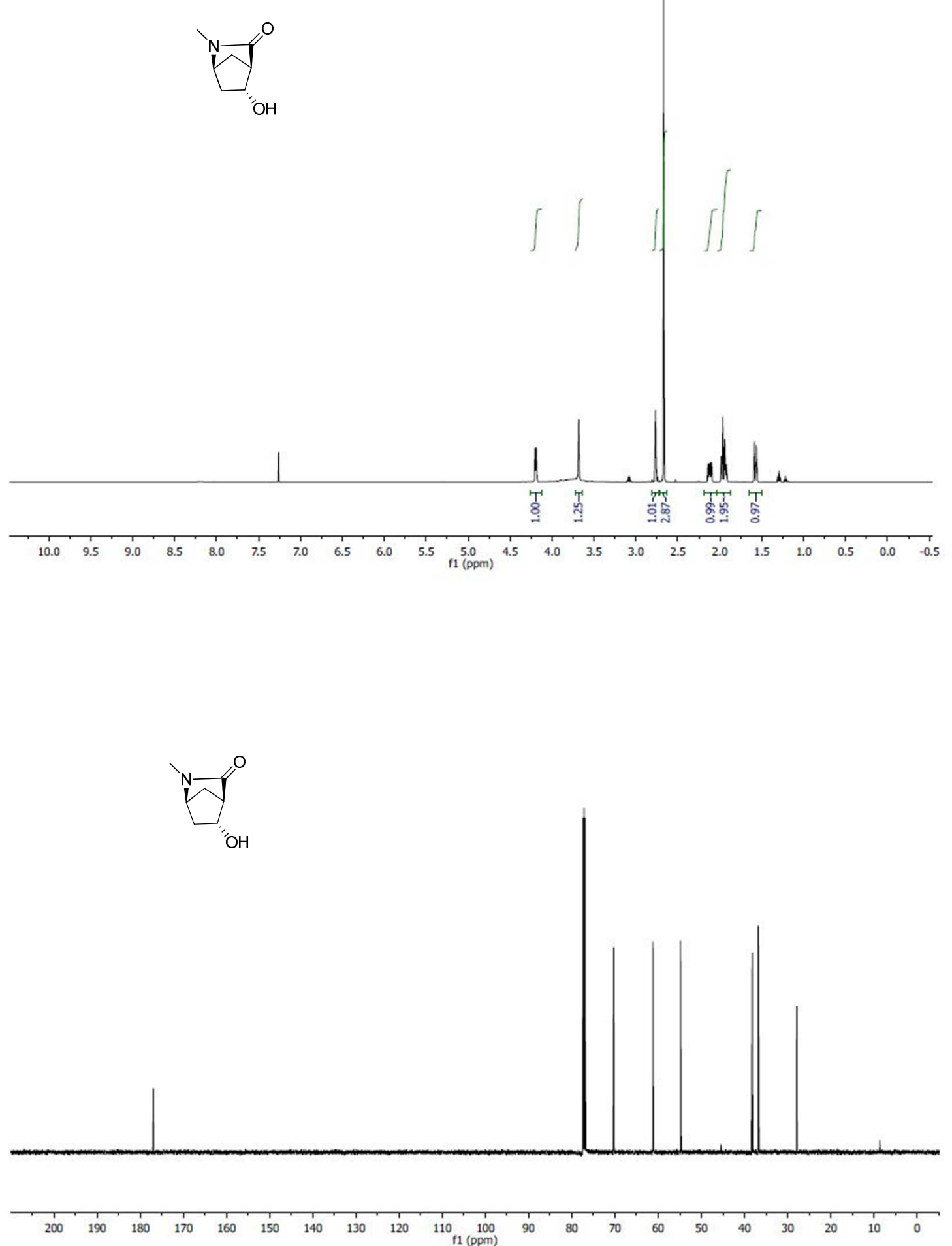
${ }^{1} \mathrm{H}$ - and ${ }^{13} \mathrm{C}-\mathrm{NMR}$ of compound $\mathbf{4 b}$ in $\mathrm{d}_{6}$-DMSO
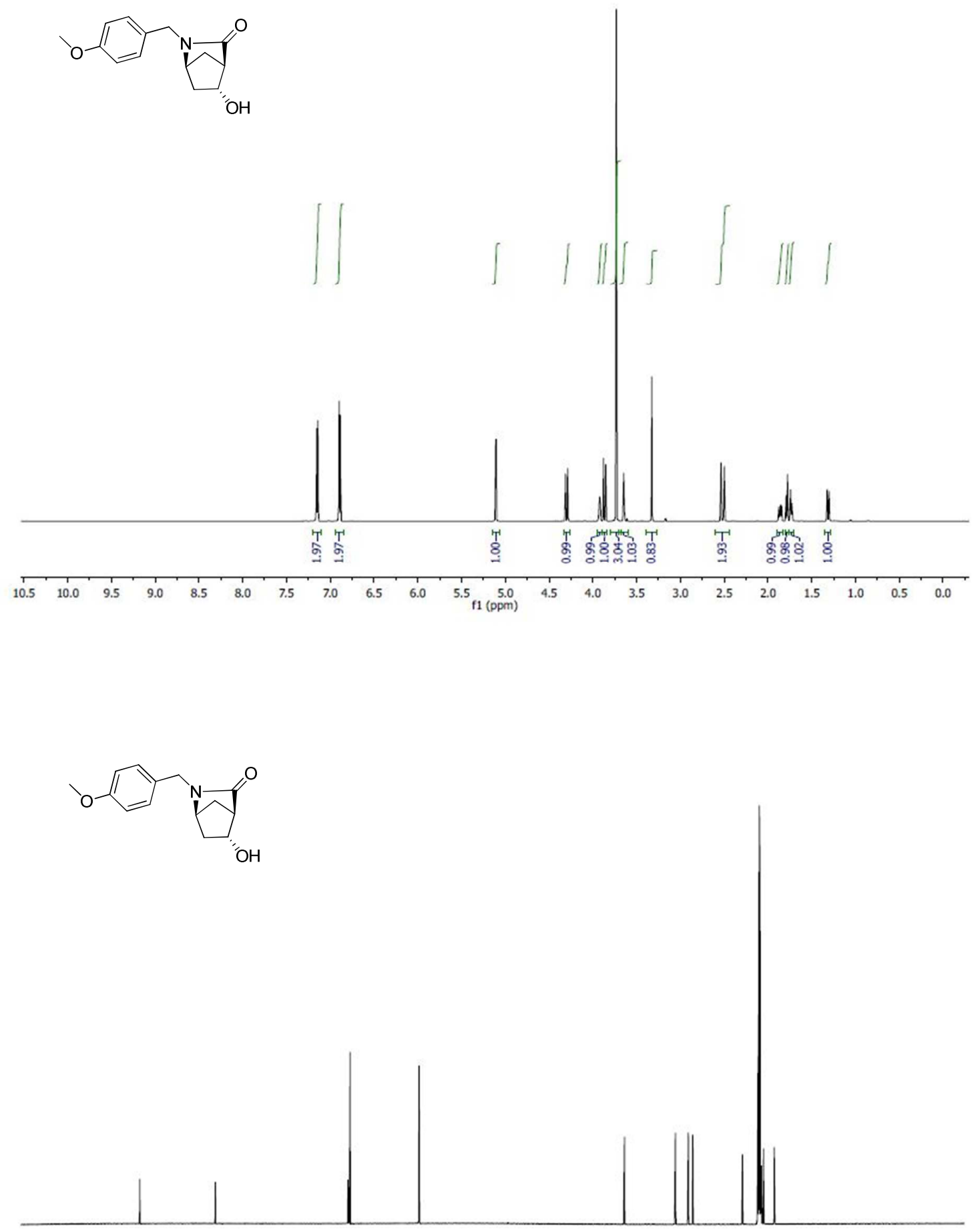

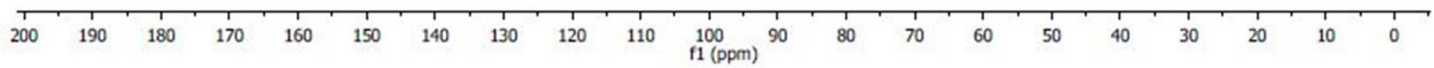


${ }^{1} \mathrm{H}$ - and ${ }^{13} \mathrm{C}-\mathrm{NMR}$ of compound $\mathbf{5 a}$ in $\mathrm{CDCl}_{3}$
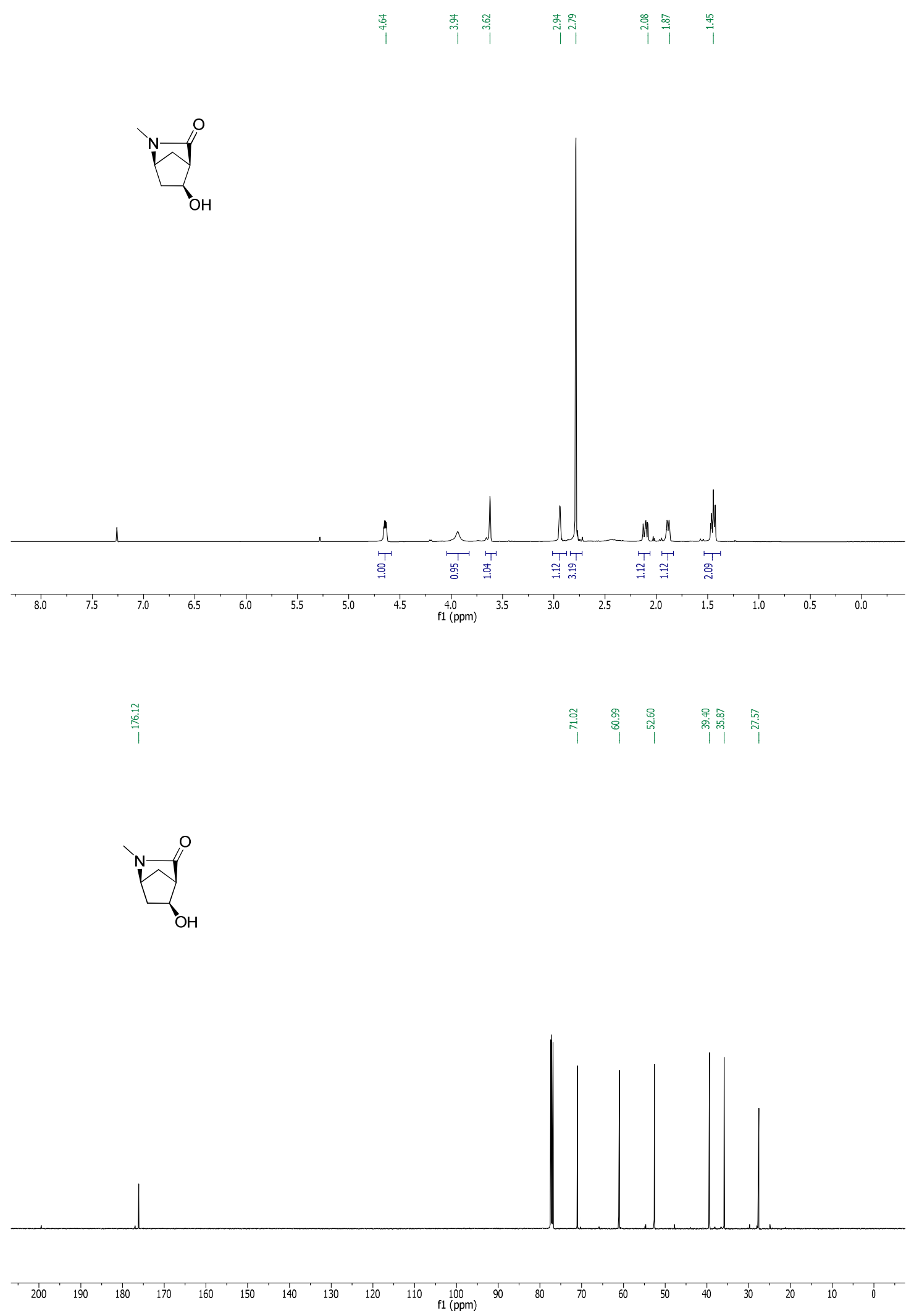
${ }^{1} \mathrm{H}$ - and ${ }^{13} \mathrm{C}-\mathrm{NMR}$ of compound $\mathbf{5 b}$ in $\mathrm{CDCl}_{3}$
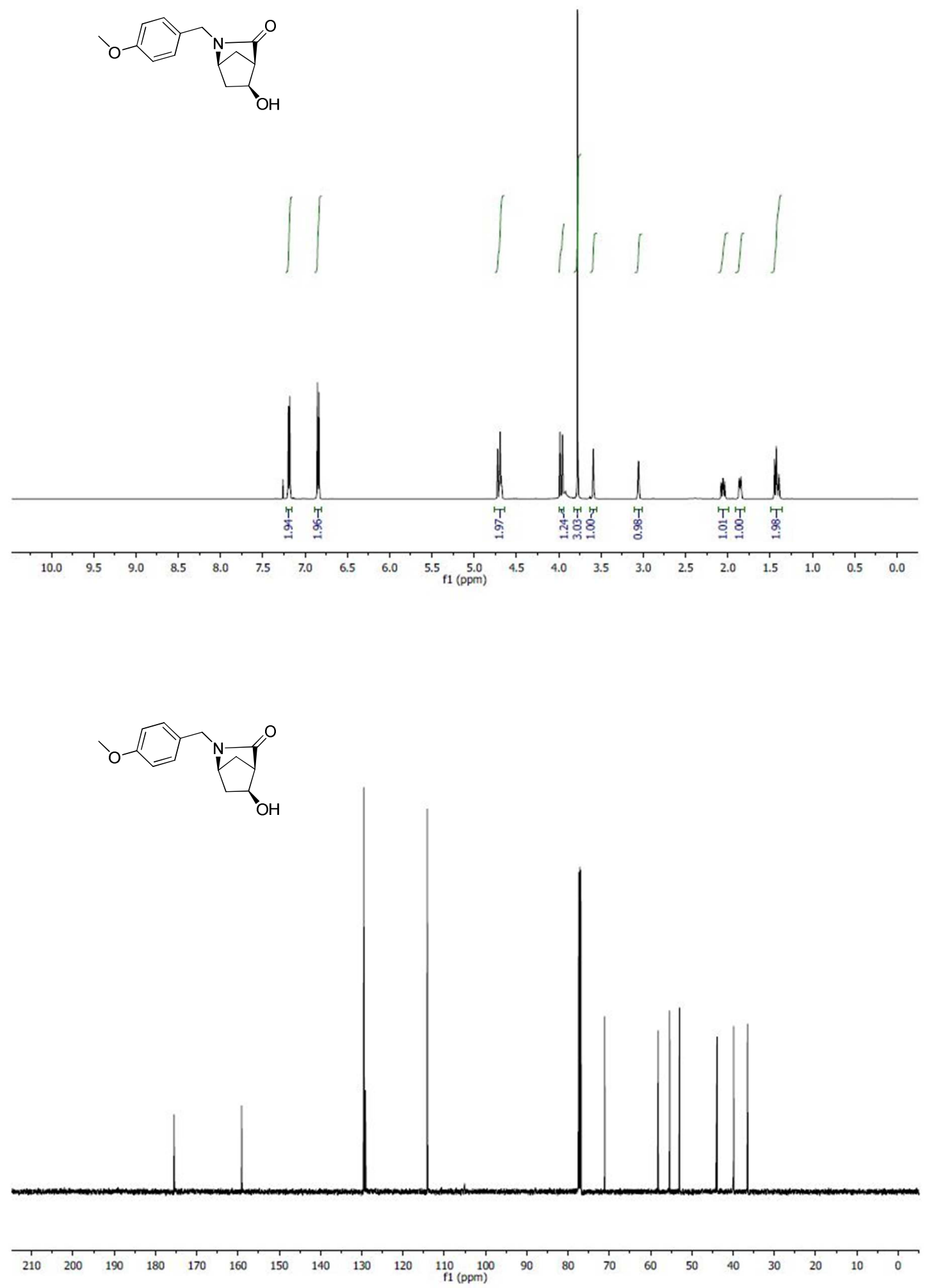
${ }^{1} \mathrm{H}$ - and ${ }^{13} \mathrm{C}$-NMR of compound 6 in $\mathrm{CDCl}_{3}$
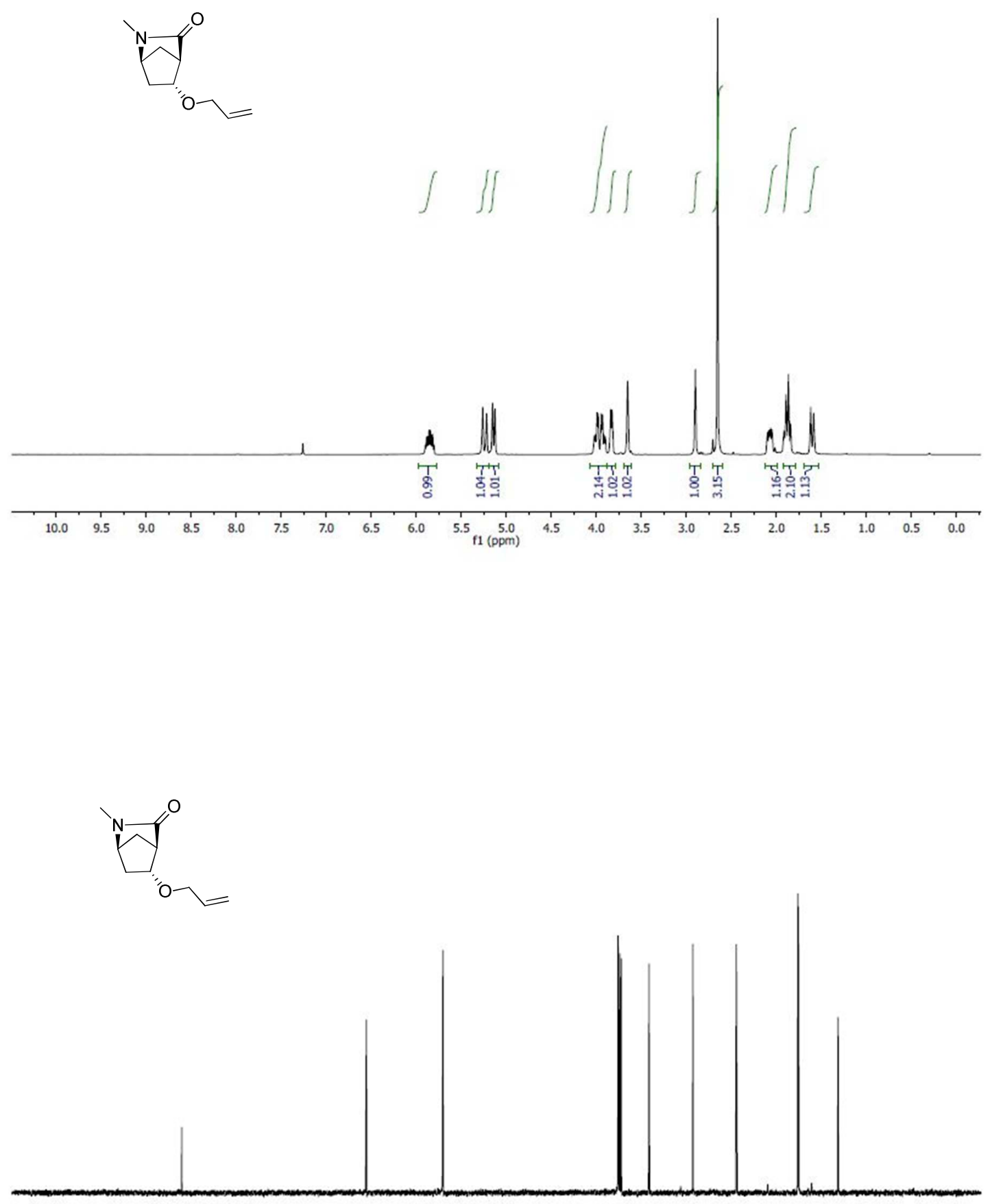
${ }^{1} \mathrm{H}$ - and ${ }^{13} \mathrm{C}$-NMR of compound 7 in $\mathrm{CDCl}_{3}$
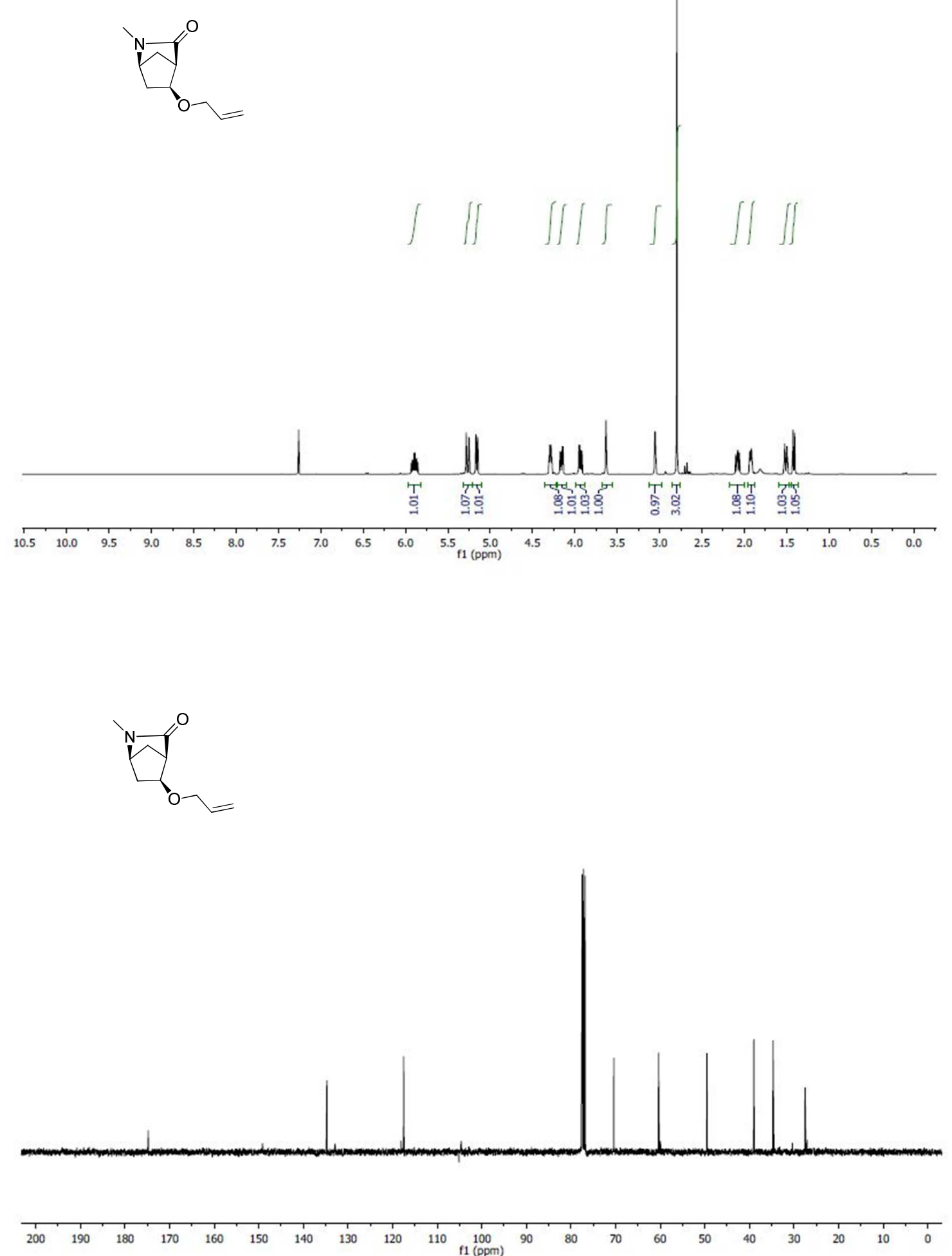
${ }^{1} \mathrm{H}$ - and ${ }^{13} \mathrm{C}$-NMR of compound $\mathbf{8 a}$ in $\mathrm{CDCl}_{3}$
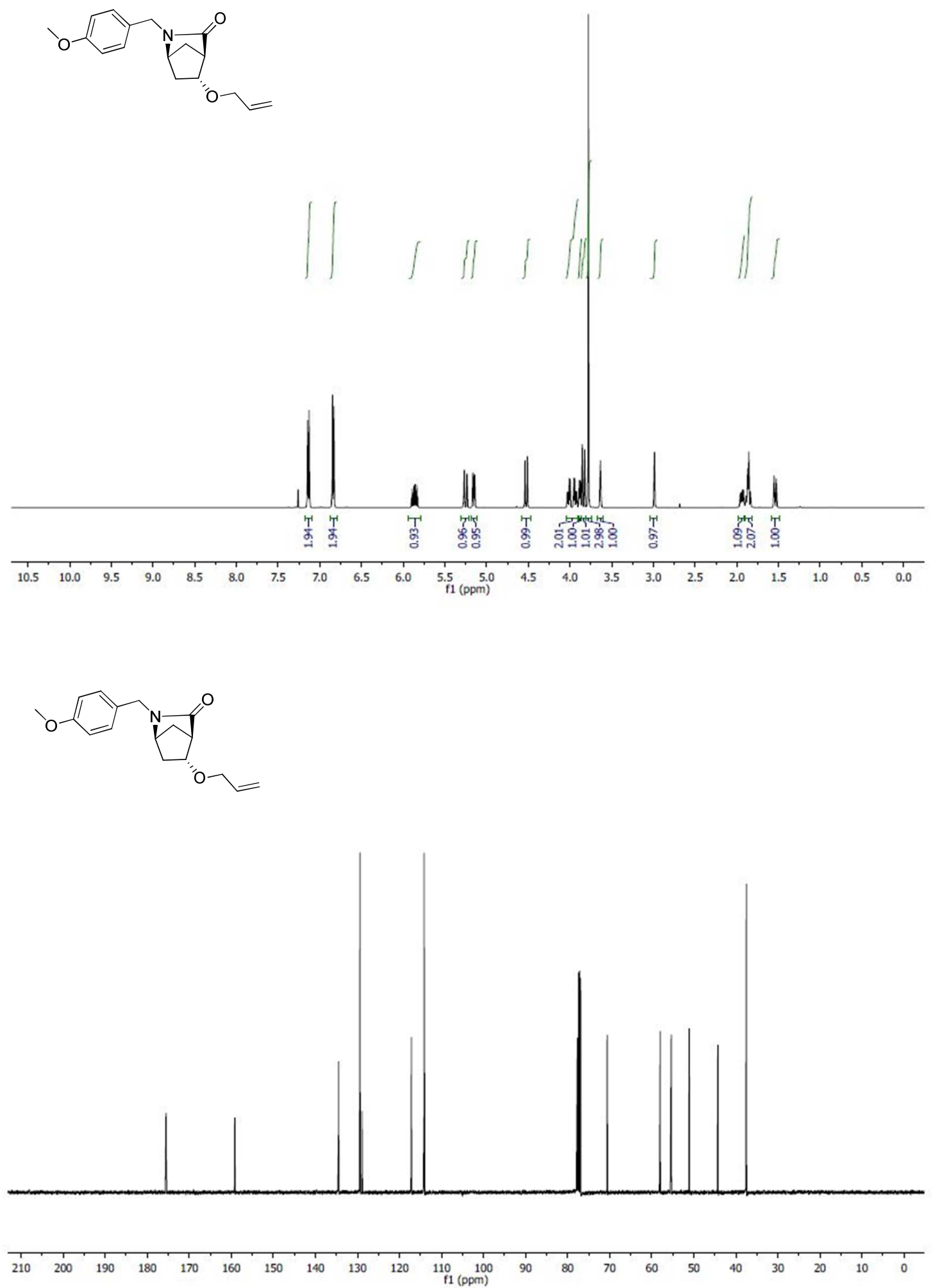
${ }^{1} \mathrm{H}$ - and ${ }^{13} \mathrm{C}-\mathrm{NMR}$ of compound $\mathbf{8 b}$ in $\mathrm{CDCl}_{3}$
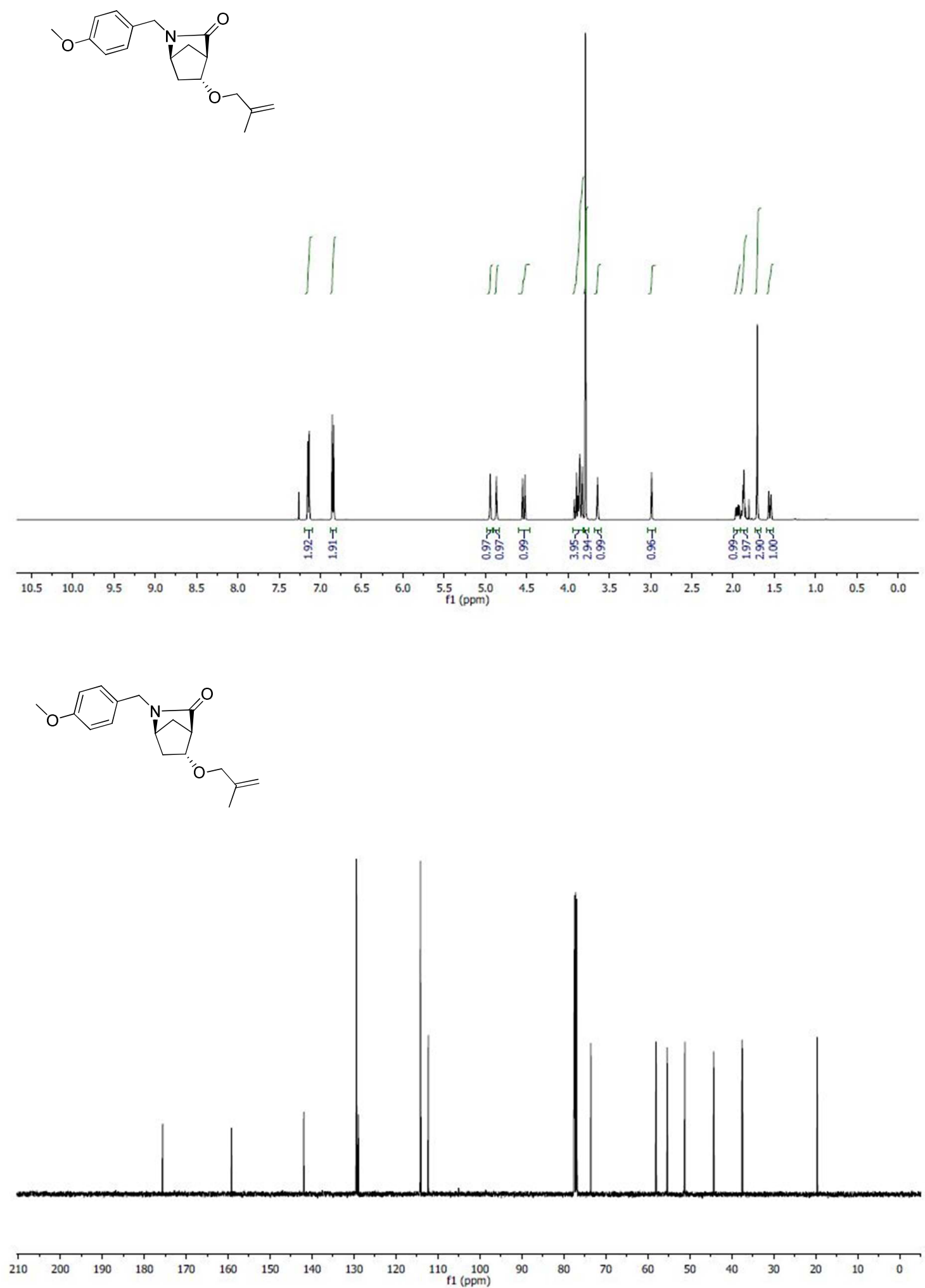
${ }^{1} \mathrm{H}$ - and ${ }^{13} \mathrm{C}$-NMR of compound $8 \mathbf{c}$ in $\mathrm{CDCl}_{3}$
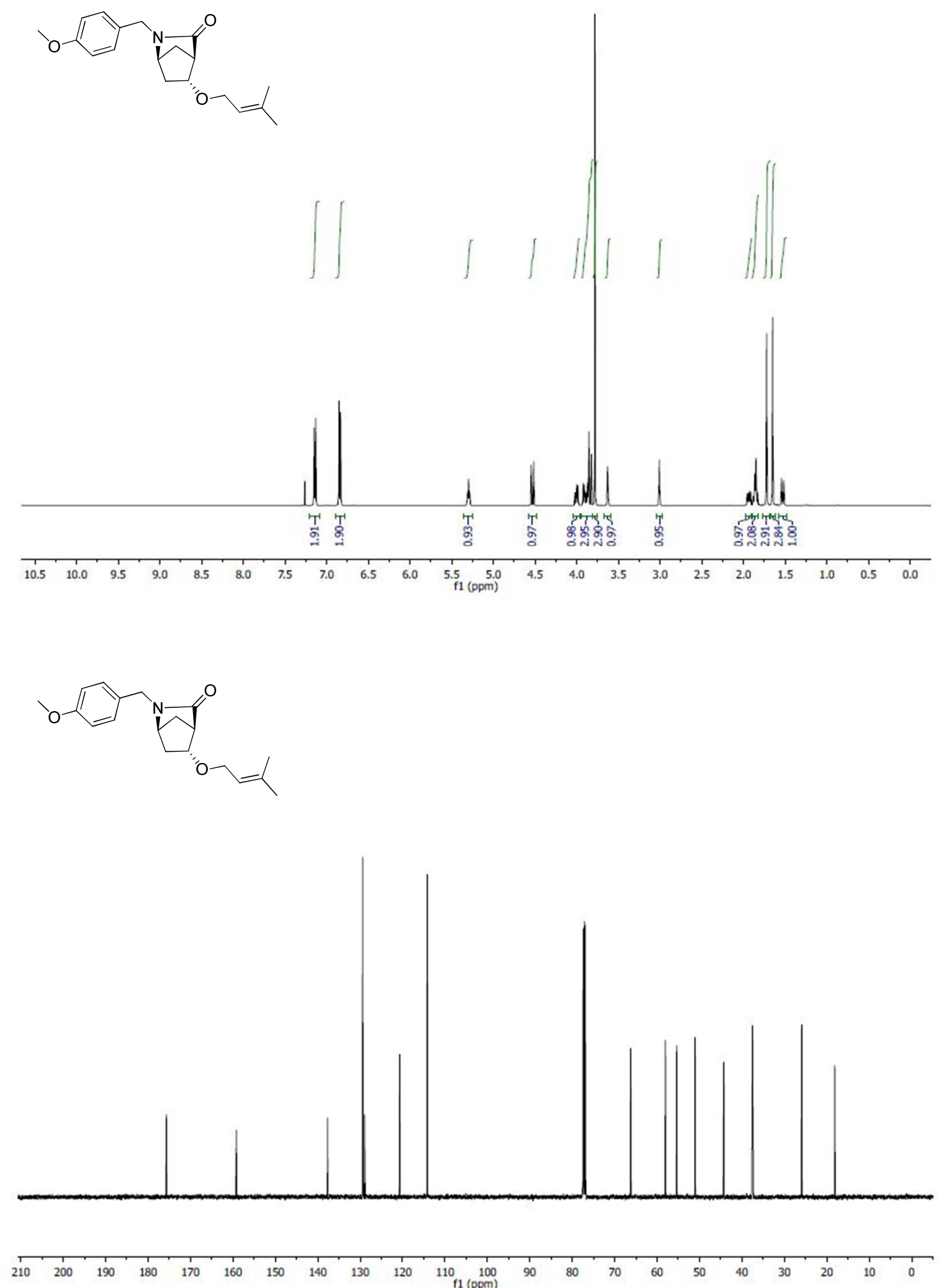
${ }^{1} \mathrm{H}$ - and ${ }^{13} \mathrm{C}-\mathrm{NMR}$ of compound $\mathbf{8 d}$ in $\mathrm{CDCl}_{3}$
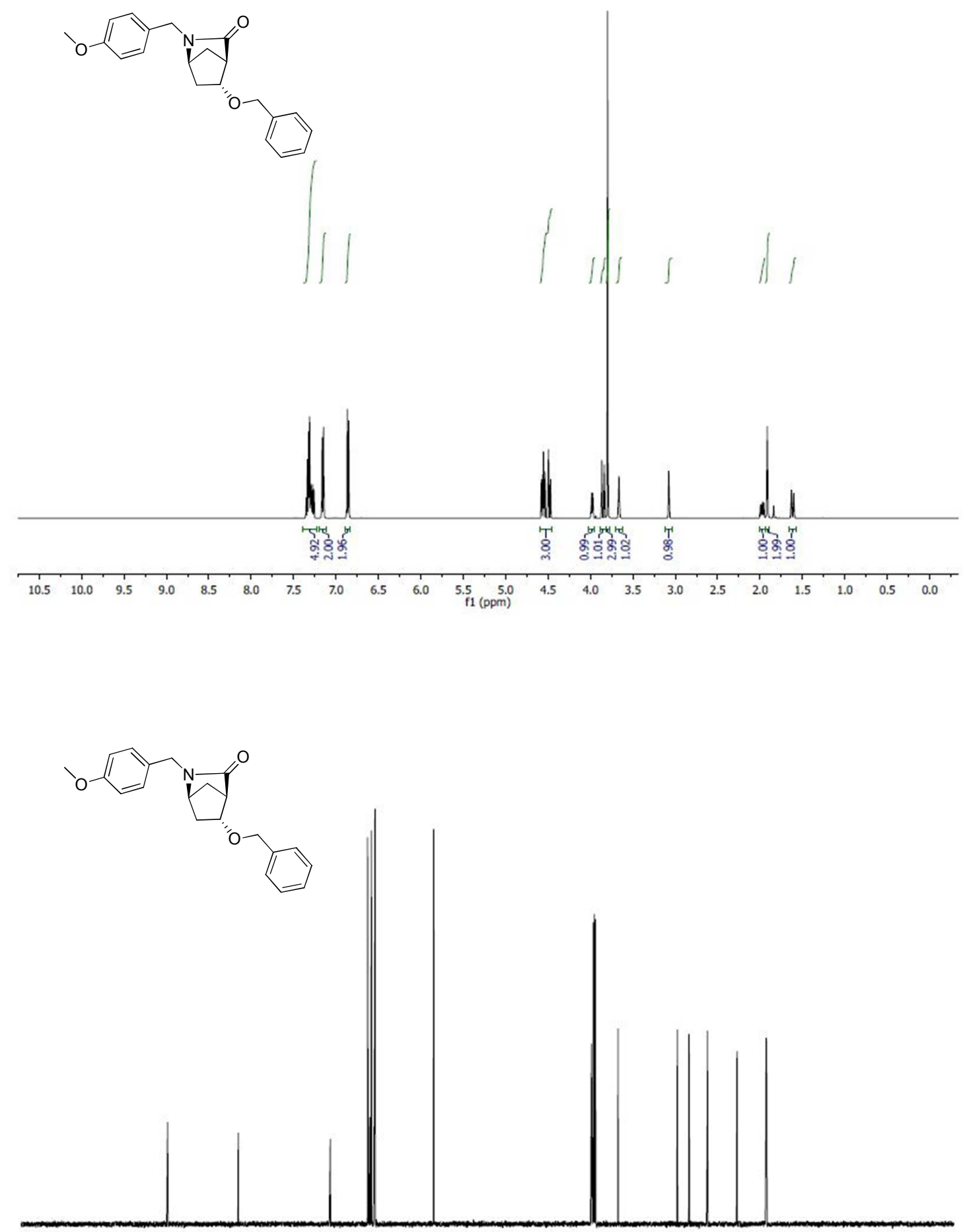
${ }^{1} \mathrm{H}$ - and ${ }^{13} \mathrm{C}$-NMR of compound $8 \mathrm{e}$ in $\mathrm{CDCl}_{3}$
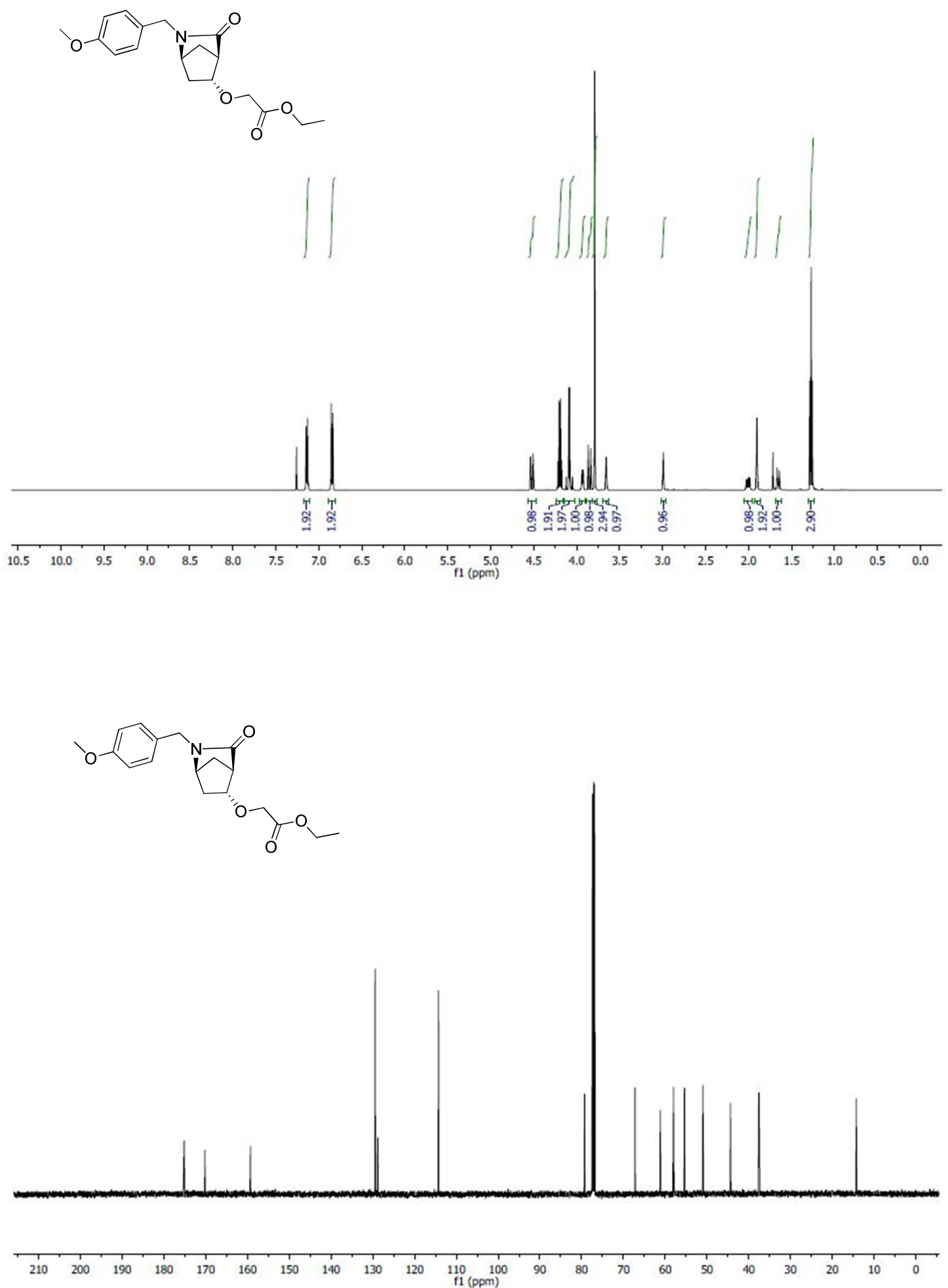
${ }^{1} \mathrm{H}$ - and ${ }^{13} \mathrm{C}-\mathrm{NMR}$ of compound $\mathbf{8 f}$ in $\mathrm{CDCl}_{3}$
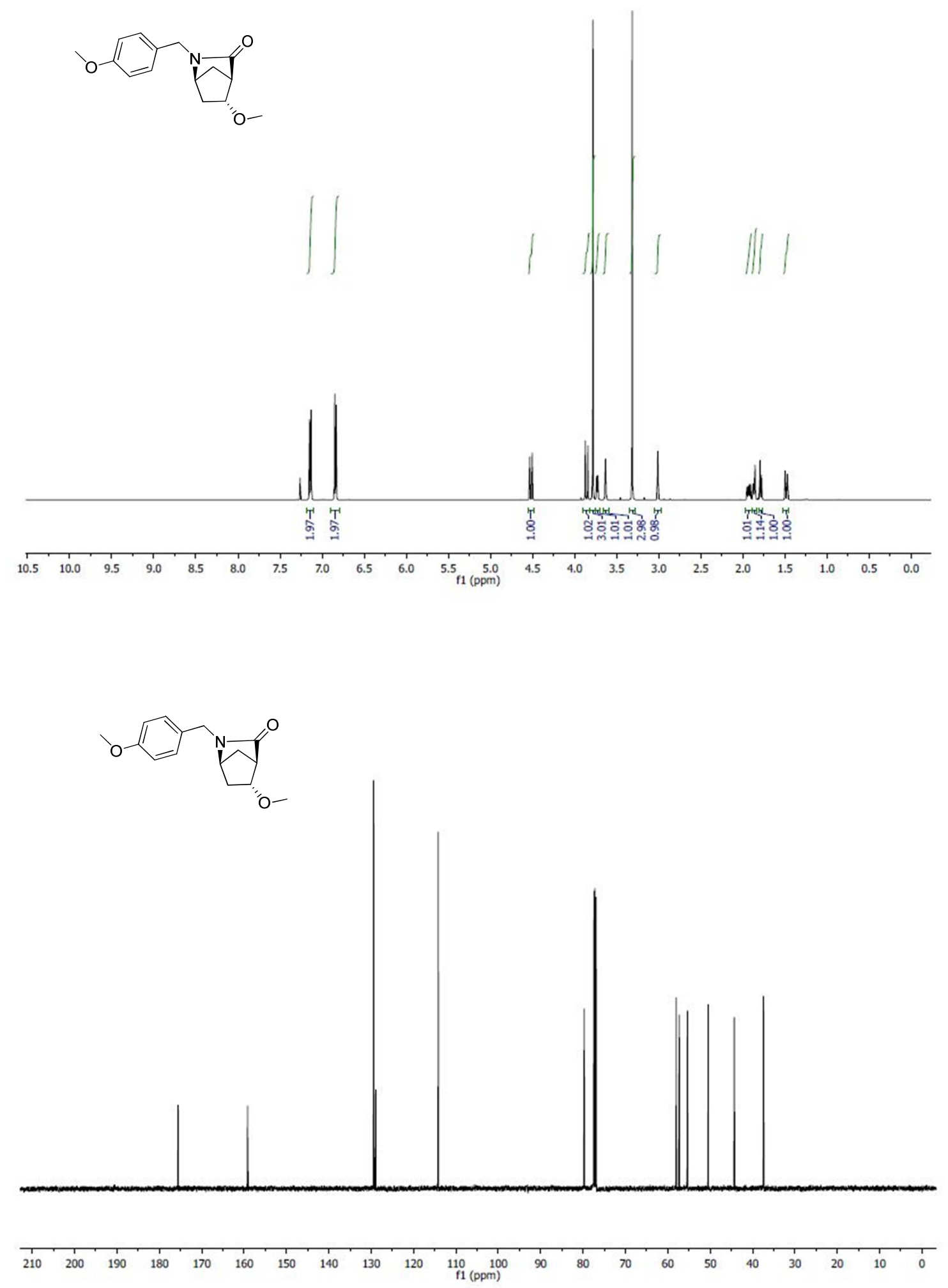
${ }^{1} \mathrm{H}$ - and ${ }^{13} \mathrm{C}-\mathrm{NMR}$ of compound 9a in $\mathrm{CDCl}_{3}$
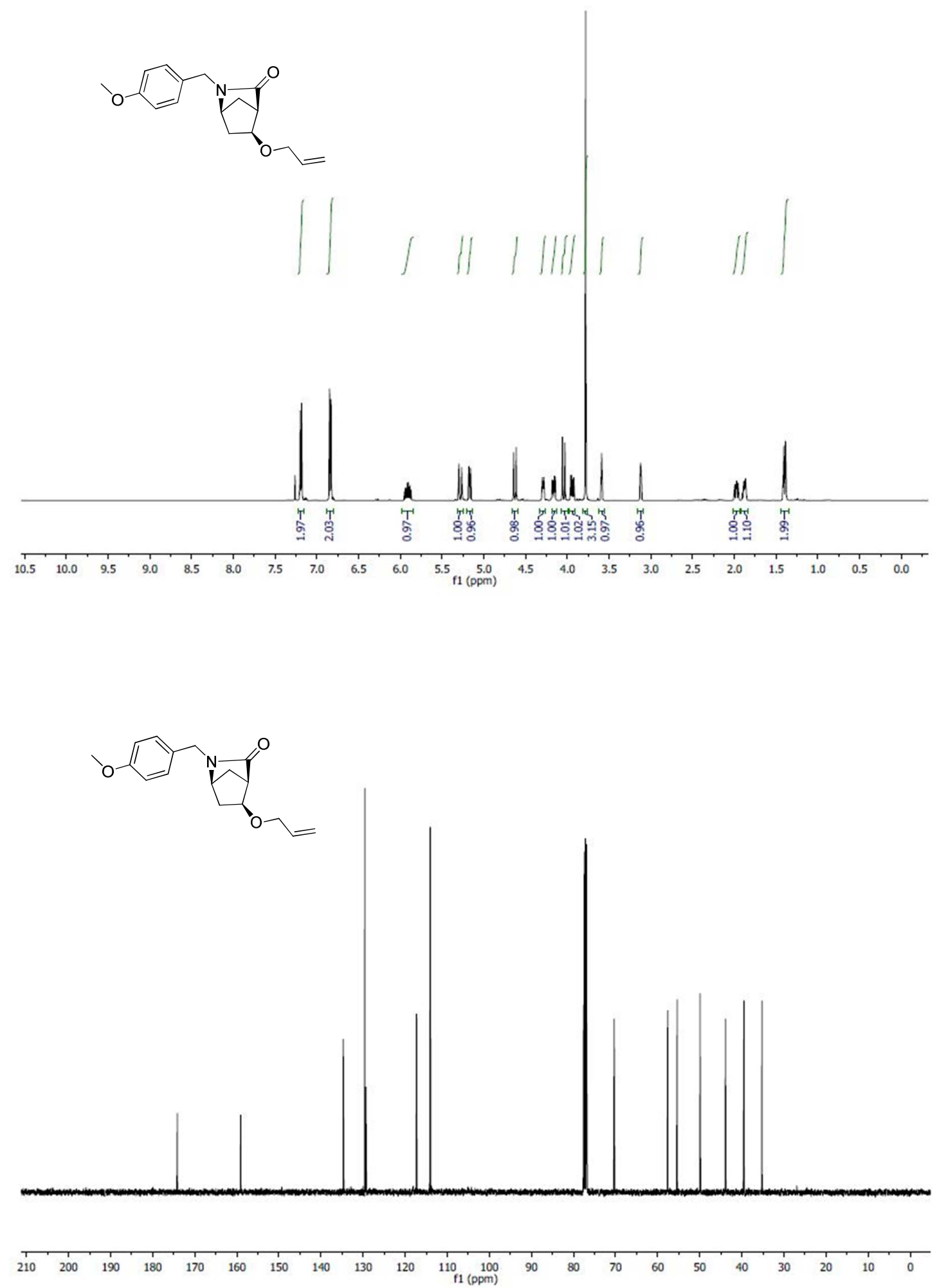
${ }^{1} \mathrm{H}$ - and ${ }^{13} \mathrm{C}-\mathrm{NMR}$ of compound $\mathbf{9 b}$ in $\mathrm{CDCl}_{3}$ :
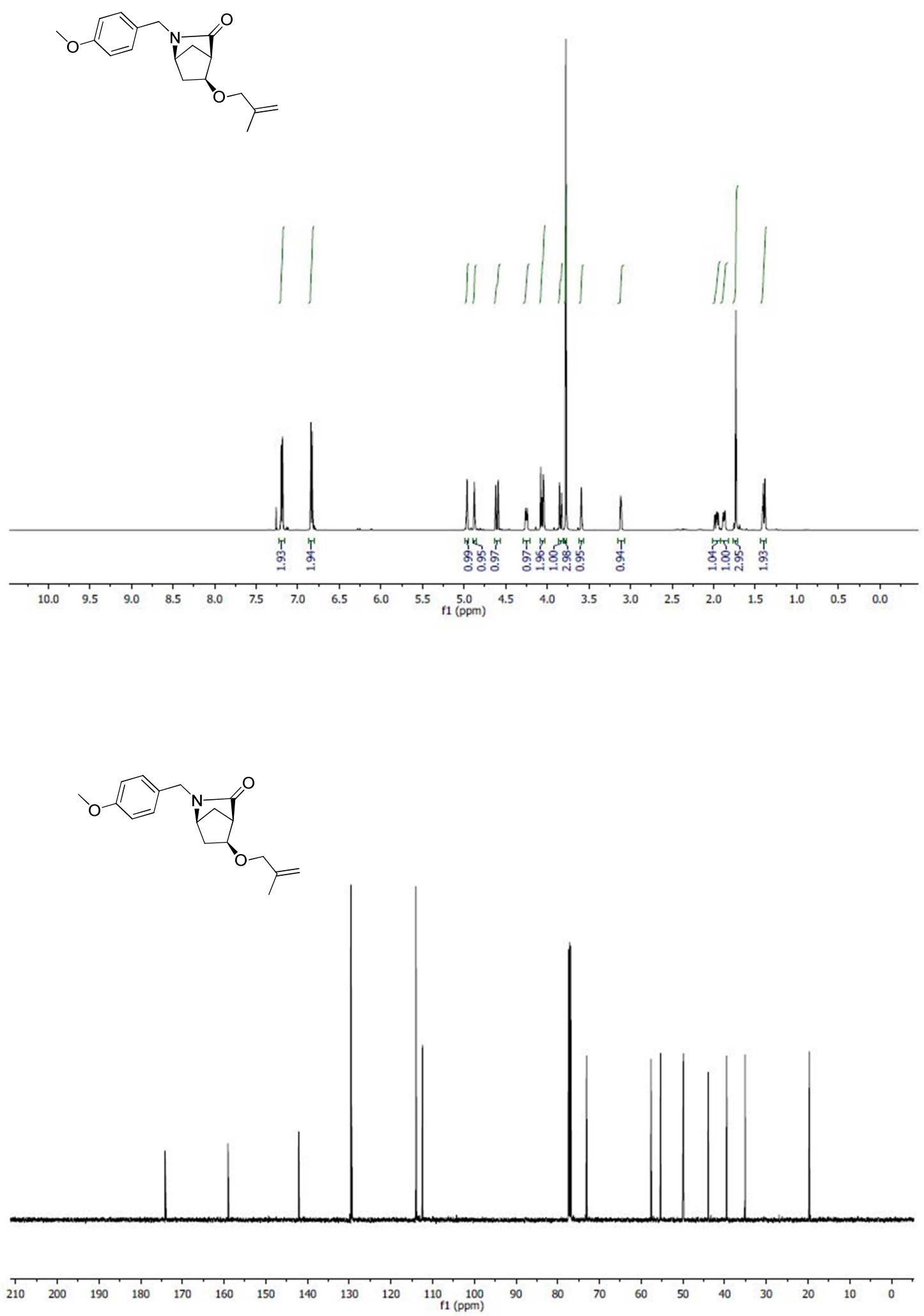
${ }^{1} \mathrm{H}$ - and ${ }^{13} \mathrm{C}-\mathrm{NMR}$ of compound $9 \mathrm{c}$ in $\mathrm{CDCl}_{3}$
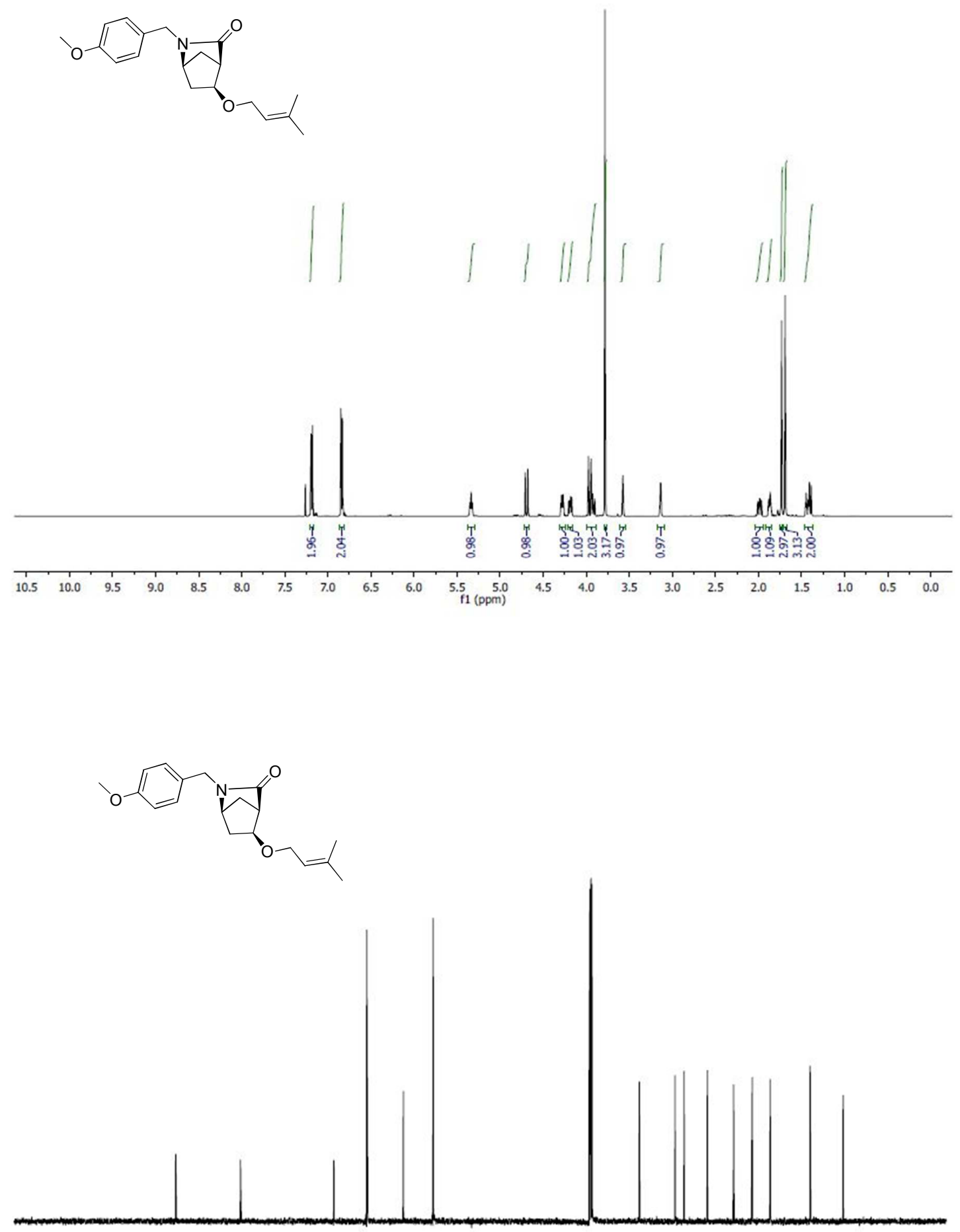

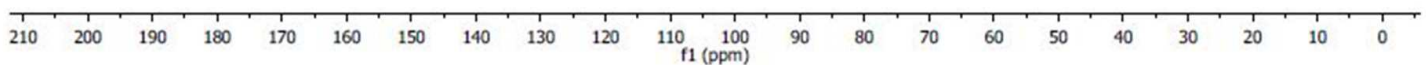


${ }^{1} \mathrm{H}$ - and ${ }^{13} \mathrm{C}-\mathrm{NMR}$ of compound 9d in $\mathrm{CDCl}_{3}$
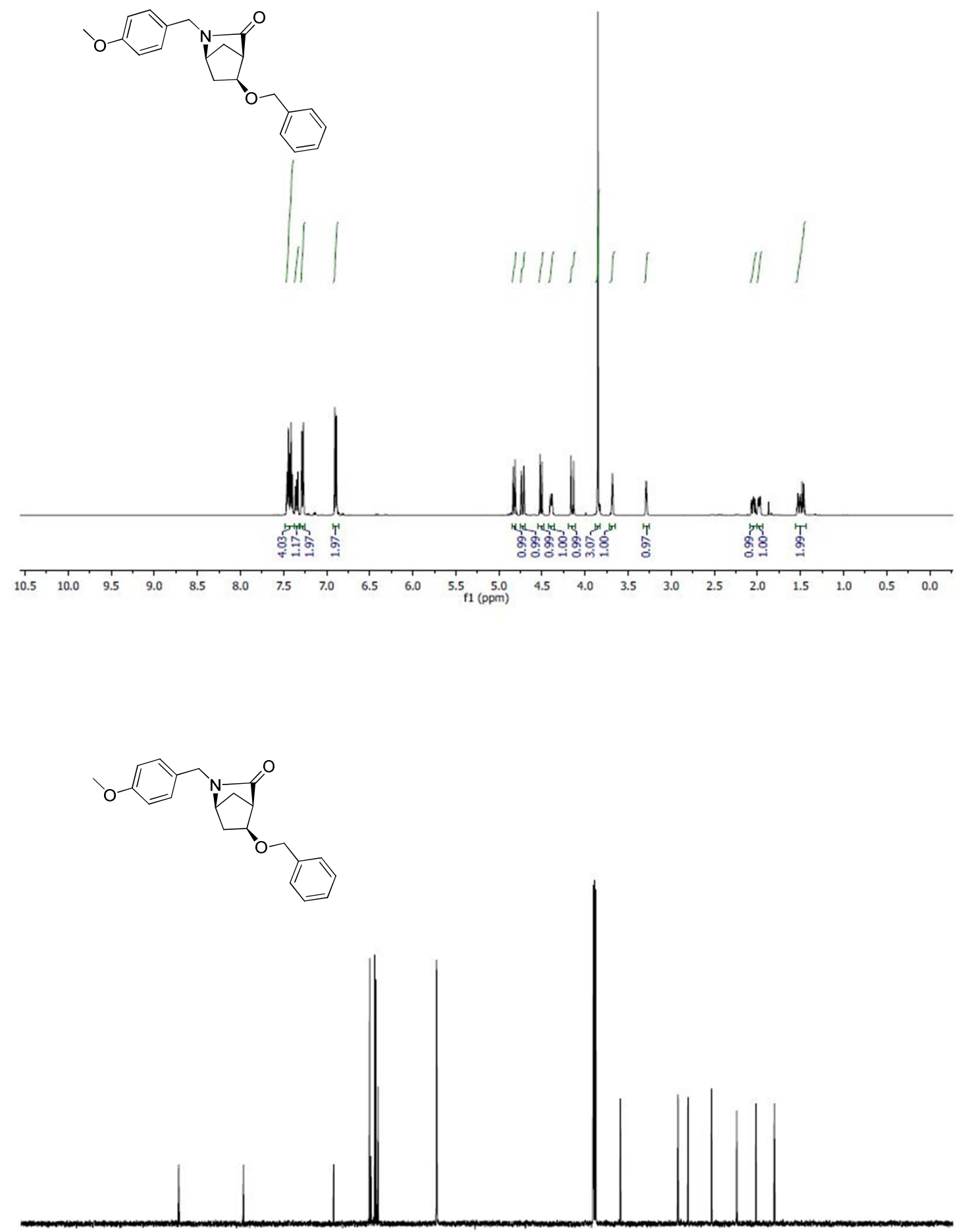
${ }^{1} \mathrm{H}$ - and ${ }^{13} \mathrm{C}-\mathrm{NMR}$ of compound $9 \mathrm{e}$ in $\mathrm{CDCl}_{3}$
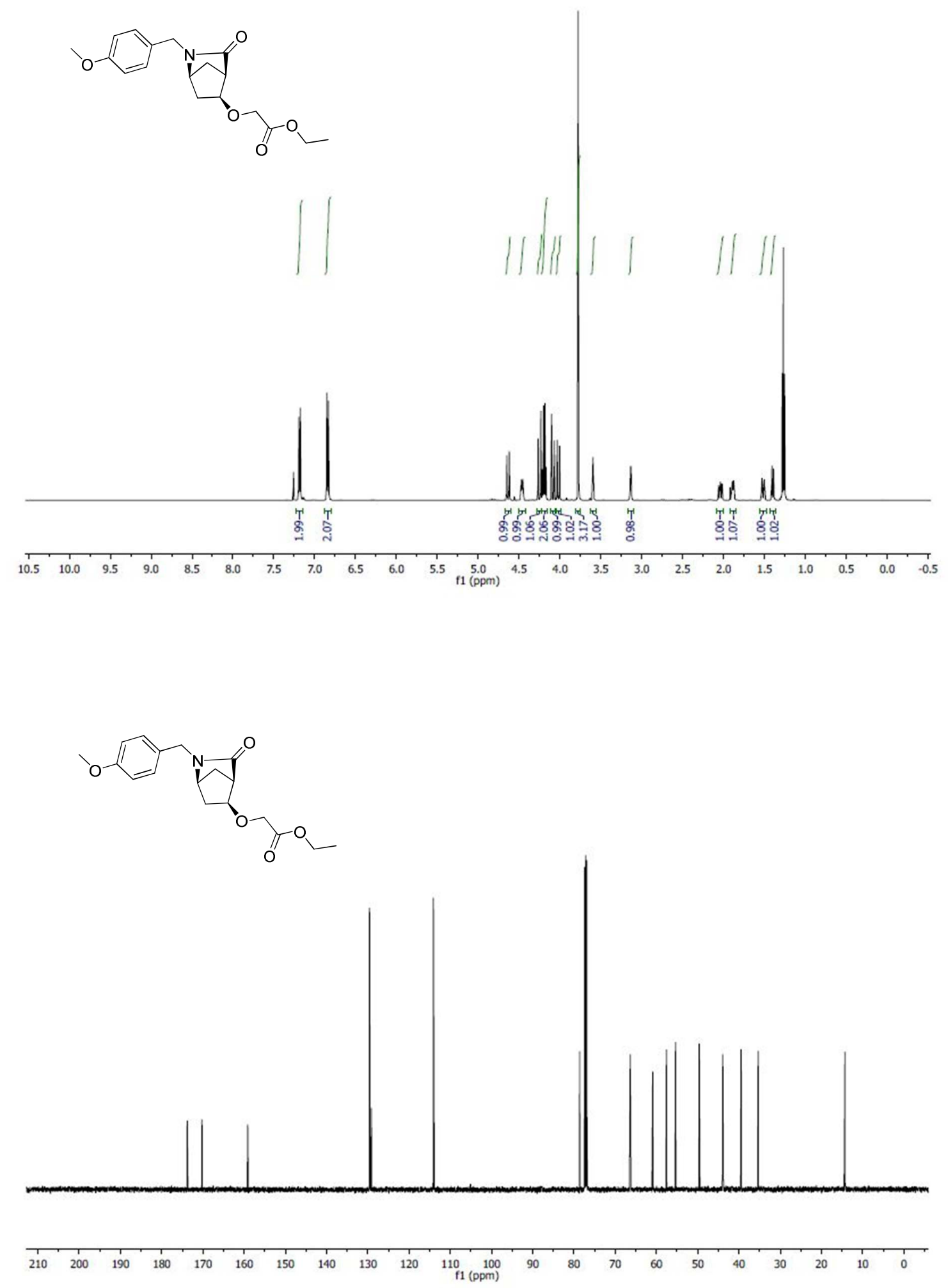
${ }^{1} \mathrm{H}$ - and ${ }^{13} \mathrm{C}-\mathrm{NMR}$ of compound $9 \mathrm{f}$ in $\mathrm{CDCl}_{3}$
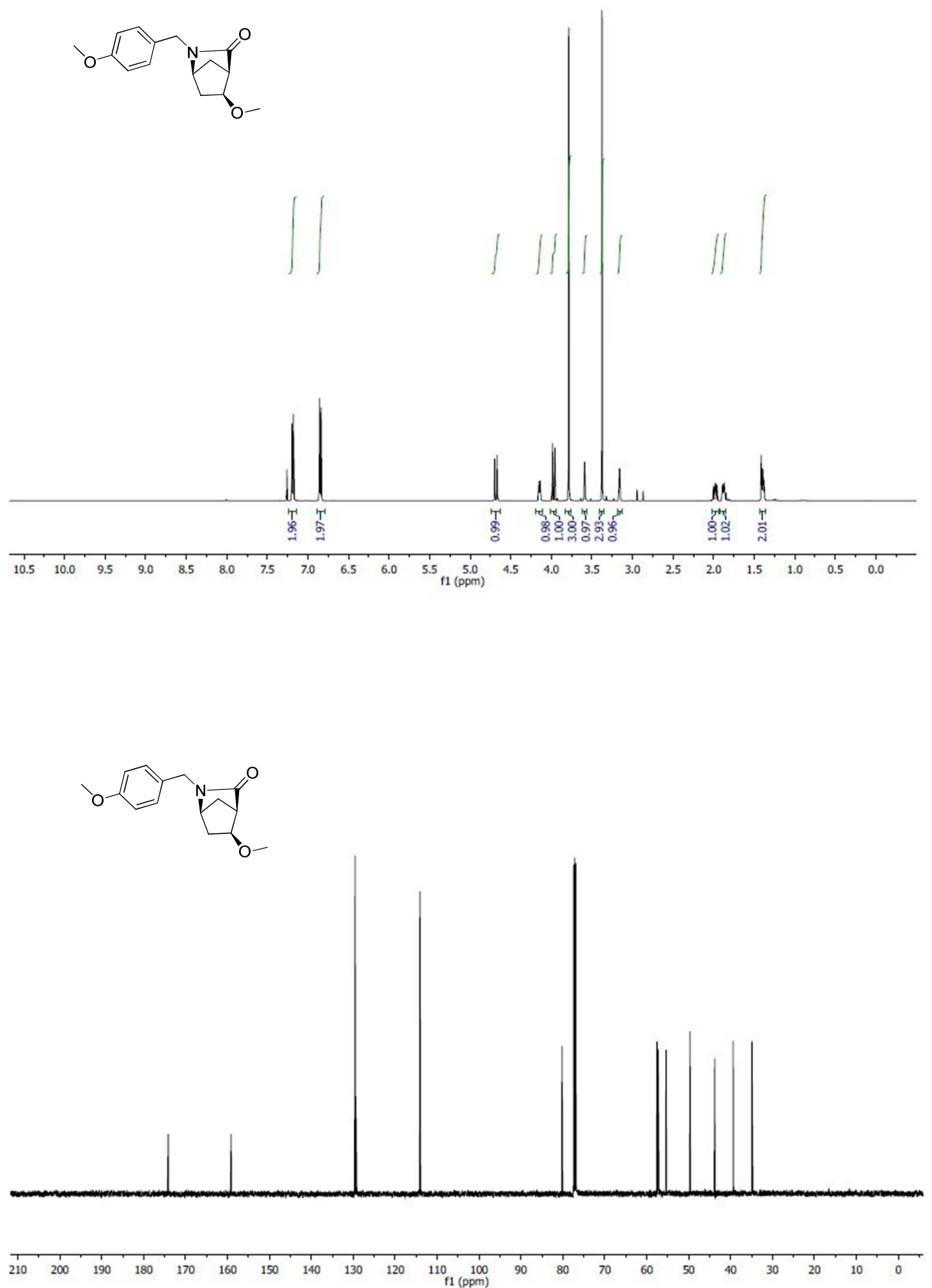
${ }^{1} \mathrm{H}$ - and ${ }^{13} \mathrm{C}-\mathrm{NMR}$ of compound 14 in $\mathrm{CDCl}_{3}$
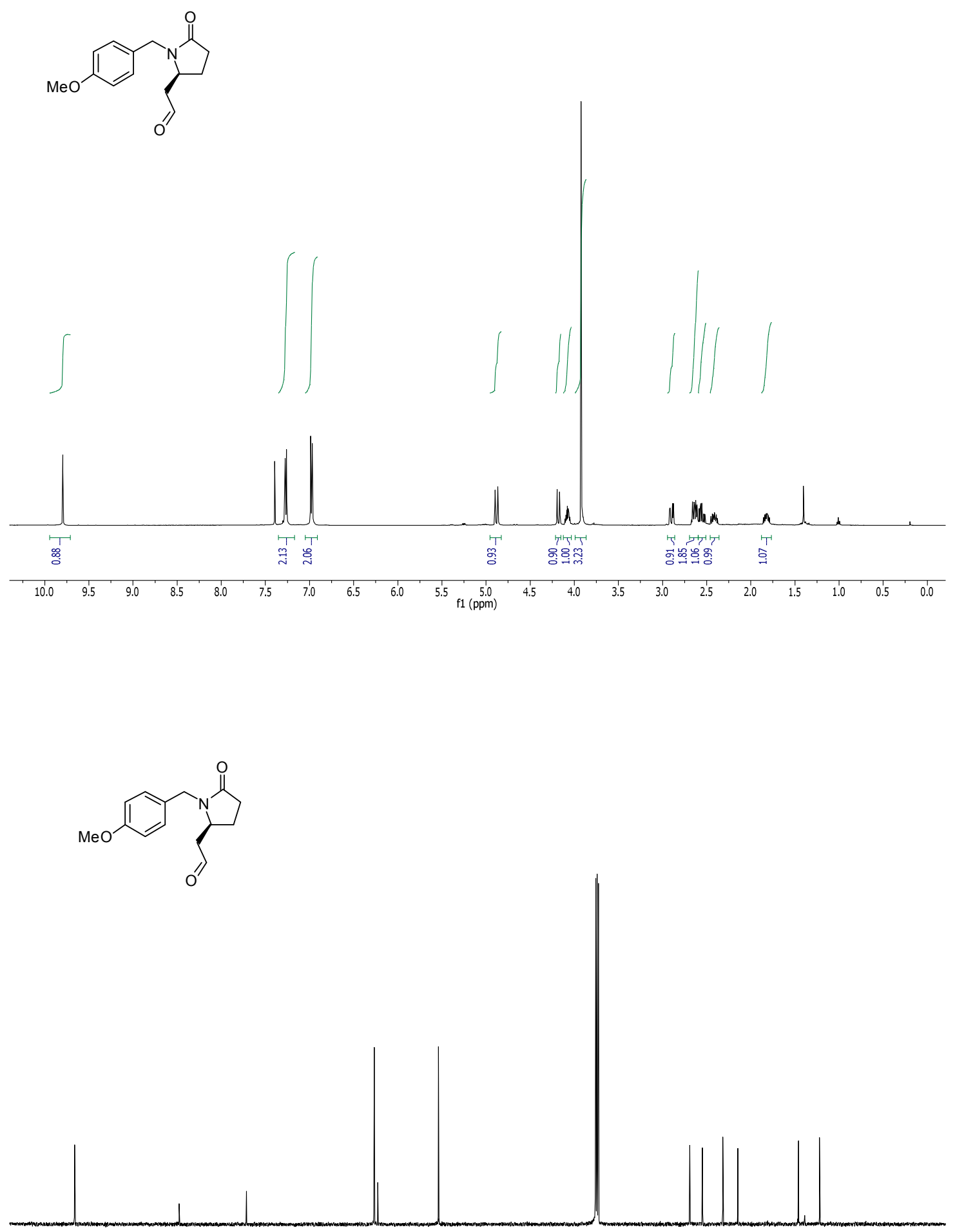

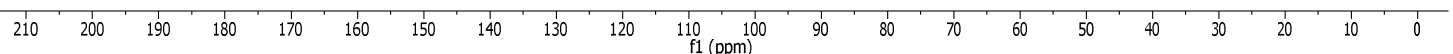


NMR-study of intermediate 12 DMSO- $d_{6}$ :
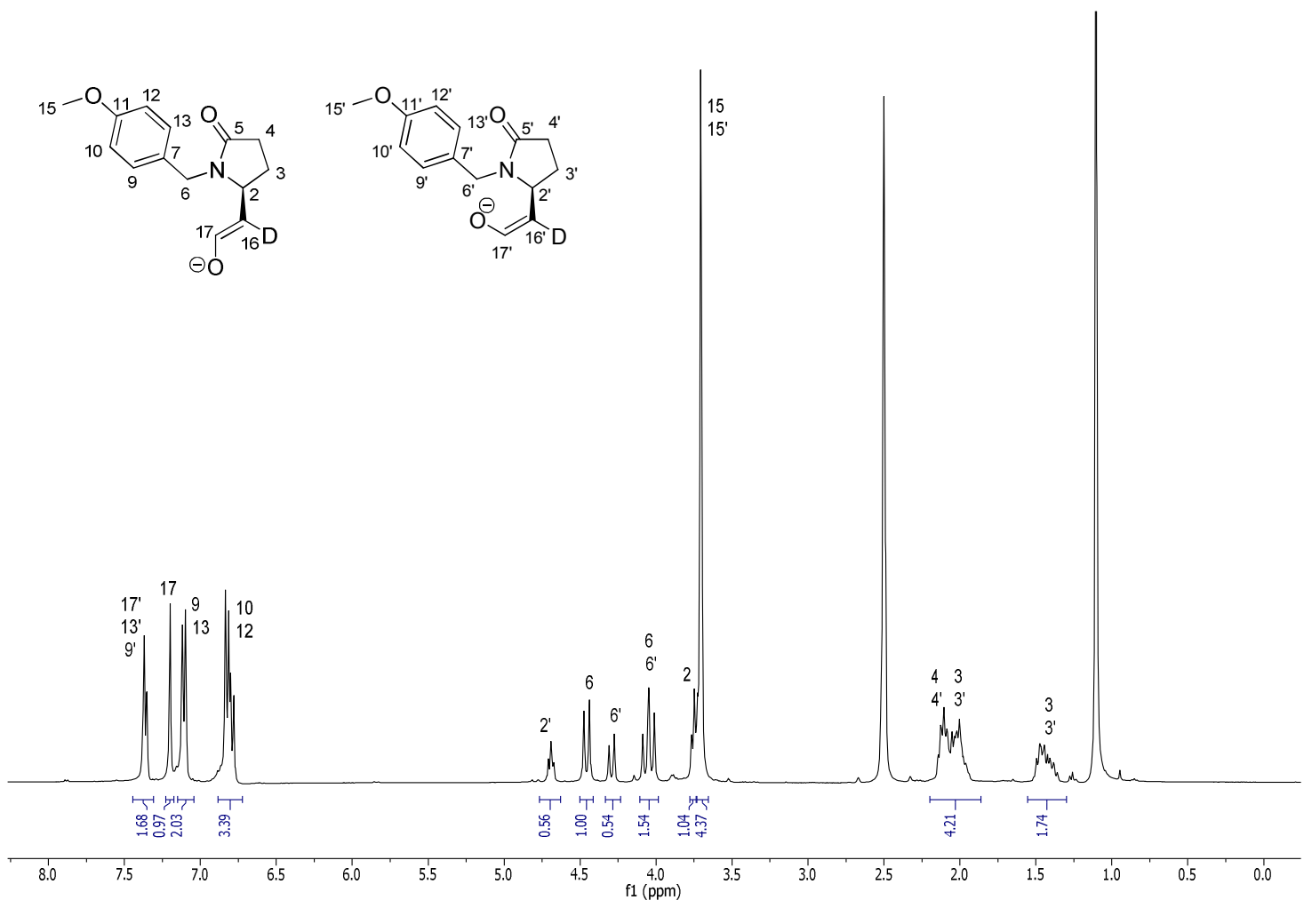

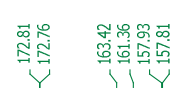

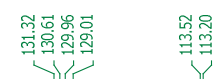

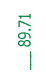

(1)
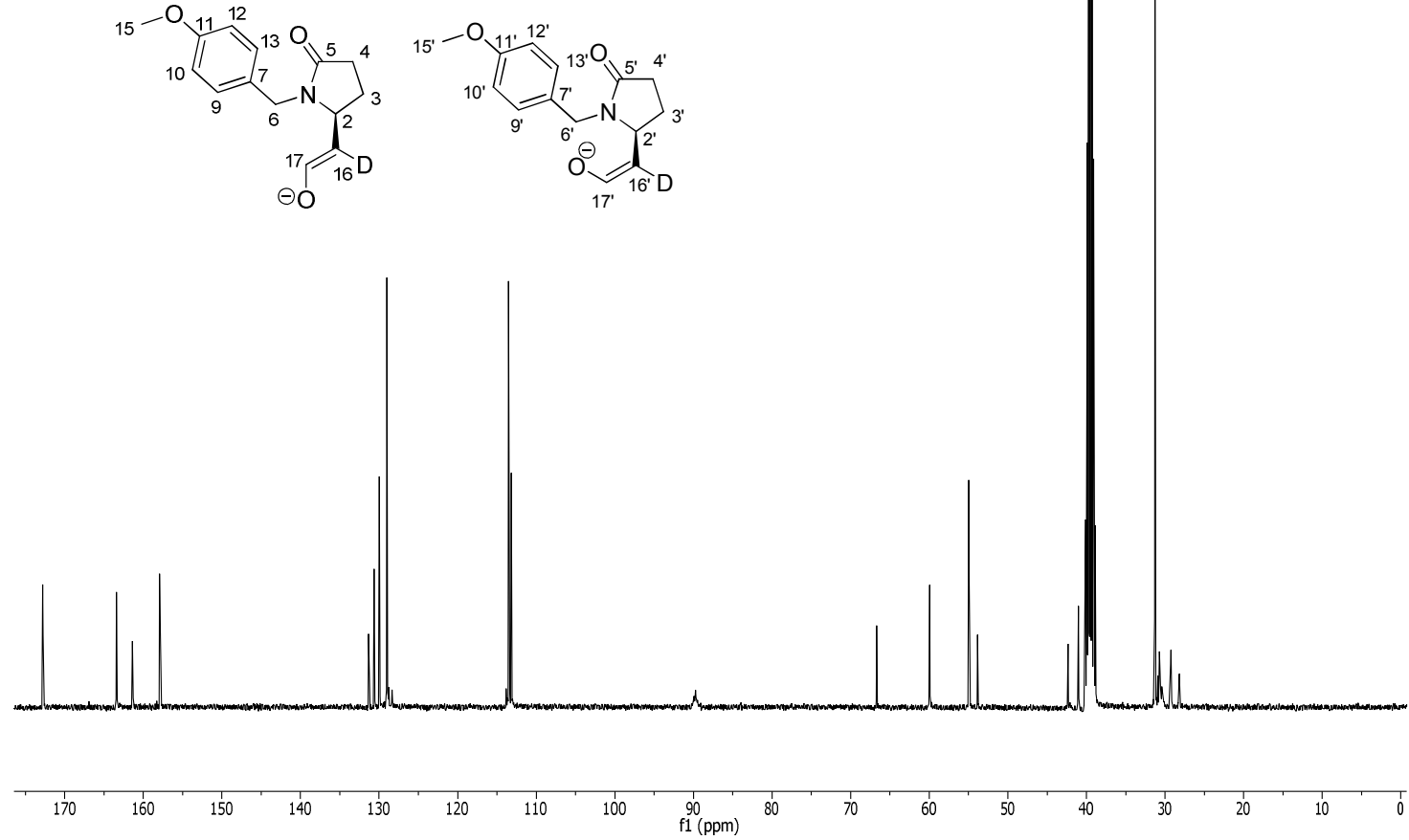
ADEQUATE-spectrum of intermediate 12 in DMSO- $d_{6}$ :

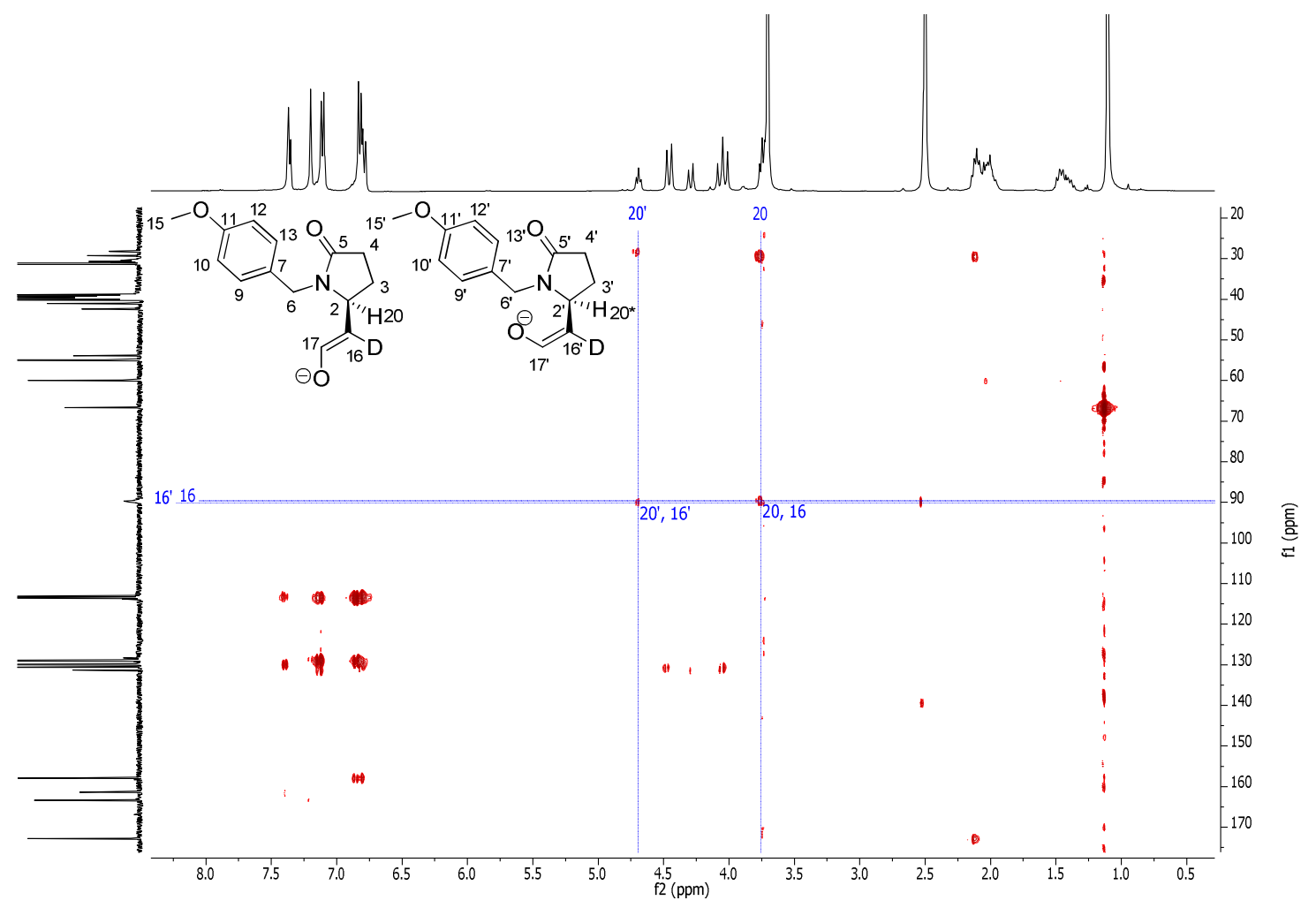

2D-ROE-spectrum of intermediate 12 in DMSO- $d_{6}(600 \mathrm{MHz})$ :

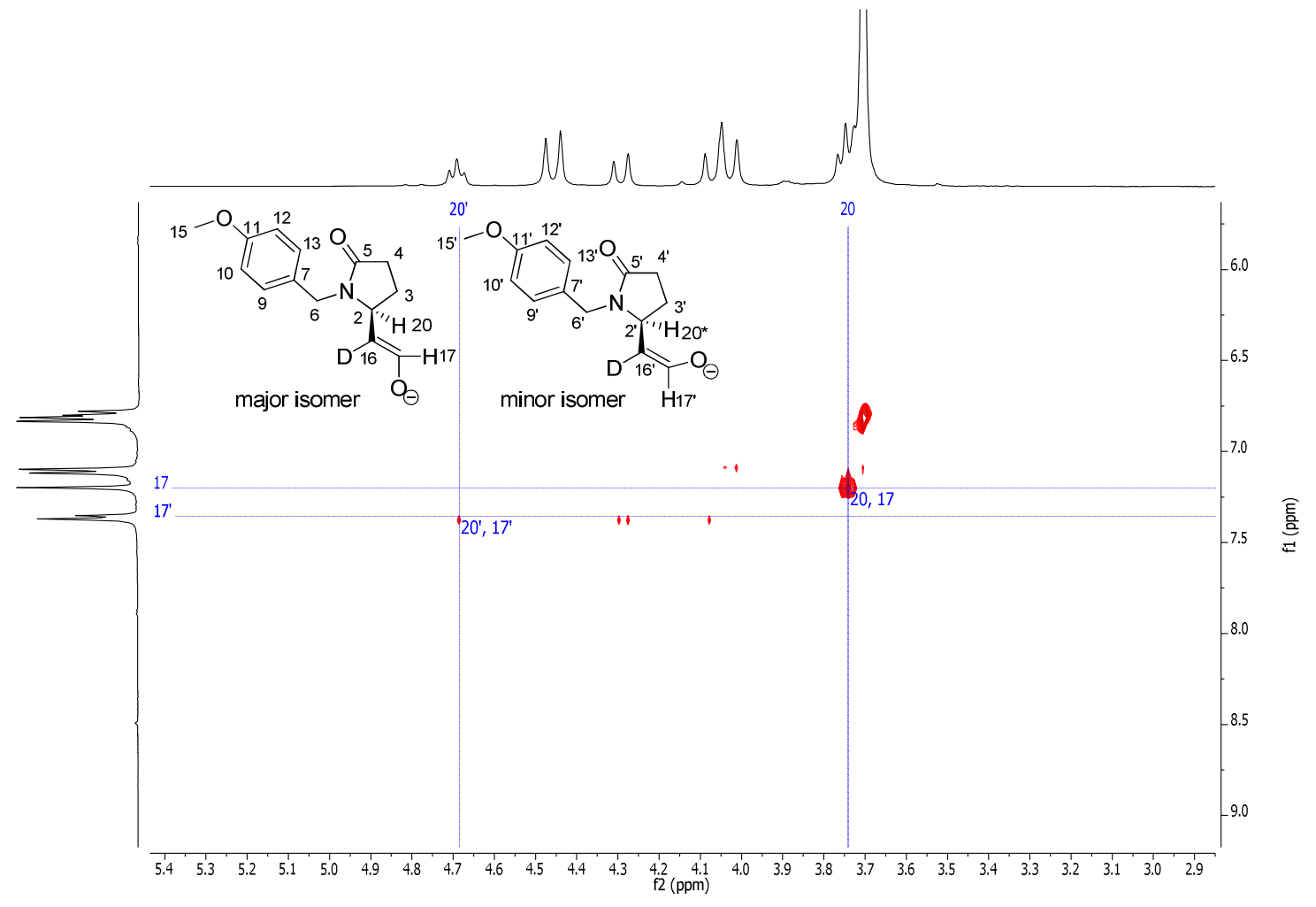

